\title{
Detection of Soot Using a Resistivity Sensor Device Employing Thermophoretic Particle Deposition
}

\author{
Doina Lutic, ${ }^{1,2,3}$ Joakim Pagels, ${ }^{1}$ Robert Bjorklund, ${ }^{2}$ Peter Josza, ${ }^{4}$ \\ Jacobus H. Visser, ${ }^{5}$ Ann W. Grant, ${ }^{4}$ Mats L. Johansson, ${ }^{6}$ Jaska Paaso, ${ }^{7}$ \\ Per-Erik Fägerman, ${ }^{8}$ Mehri Sanati, ${ }^{1}$ and Anita Lloyd Spetz ${ }^{2}$ \\ ${ }^{1}$ Ergonomics and Aerosol Technology, Lund University, Box 118, 22100 Lund, Sweden \\ ${ }^{2}$ Department of Physics, Chemistry and Biology, Linköping University, 58183 Linköping, Sweden \\ ${ }^{3}$ Department of Chemistry, Al. I. Cuza University of Iasi, 11 Bd. Carol I, 700506 Iasi, Romania \\ ${ }^{4}$ Department 06100, Volvo Technology Corporation, CTP, Sven Hultins Gata 9D, 41288 Göteborg, Sweden \\ ${ }^{5}$ Ford Motor Company, Dearborn, MI, USA \\ ${ }^{6}$ Advanced Engineering Diesel Department, VOLVO Cars, 97621 PV3 C1, 40531 Göteborg, Sweden \\ ${ }^{7}$ Selmic Oy, Veistämötie 15, P.O. Box 350, 90501 Oulu, Finland \\ ${ }^{8}$ Mandalon Technology AB, Westmansgatan 49, 58216 Linköping, Sweden
}

Correspondence should be addressed to Doina Lutic, doilub@yahoo.com

Received 29 January 2010; Accepted 3 May 2010

Academic Editor: Yong Xiang Li

Copyright ( 12010 Doina Lutic et al. This is an open access article distributed under the Creative Commons Attribution License, which permits unrestricted use, distribution, and reproduction in any medium, provided the original work is properly cited.

Results are reported for thermophoretic deposition of soot particles on resistivity sensors as a monitoring technique for diesel exhaust particles with the potential of improved detection limit and sensitivity. Soot with similar characteristics as from diesel exhausts was generated by a propane flame and diluted in stages. The soot in a gas flow at $240-270^{\circ} \mathrm{C}$ was collected on an interdigitated electrode structure held at a considerably lower temperature, $105-125^{\circ} \mathrm{C}$. The time delay for reaching measurable resistance values, the subsequent rate, and magnitude of resistance decrease were a function of the distance between the fingers in the electrodes and the degree of dilution of the soot containing flow. Soot deposition and subsequent removal by heating the sensor support was also performed in a real diesel exhaust. Good similarities between the behavior in our laboratory system and the real diesel exhaust were noticed.

\section{Introduction}

The soot generated by diesel engines mainly contains elemental carbon and heavy hydrocarbons, physically associated in a liquid fraction made of unburned fuel and oil, together with sulfuric acid [1]. The harmful consequences of soot on human health include respiratory and cardiovascular effects and the particles may be carcinogenic [2, 3]. Beside these health issues, soot deposition on buildings and vegetation contributes to their long-term degradation. Finally, soot influences global climate mainly by its strong absorption of solar radiation in the atmosphere.

Soot detection and measurement is an important target today for car manufacturers since the regulations concerning particle mass emission limits have been substantially lowered in recent years [4]. Detection of particle number per unit volume was recently implemented in the European emission standard, indirectly making particle size an important parameter. Chemical composition and particle size may become even more important in future legislations [5].

Modern diesel automotives are equipped with ceramic soot filters which are periodically regenerated by burn off when the accumulated soot exceeds a certain concentration, with the help of additional injected fuel and air. It is important for car manufacturers to optimize filter performance. Furthermore, requirements of on board diagnostics, OBD, of a failed filter are anticipated.

Soot particle detection and measurement on board using sensors can be achieved by several methods. Several patents $[6,7]$ indicate that the soot collection on filters, followed 
by the subsequent heating in an oxygen-rich environment to oxidize carbon particulates to carbon dioxide, in a closed measurement loop, correlated with the amount of filtered gas volume, allows the determination of the particulate concentration. The measurement of the pressure drop (015 psi range) between the two faces of a particle filter for soot containing gas flow [8] has also been used to measure the soot concentration. A photoacoustic device [9] analyzing in a differential mode the voltage issued by two identical resonators exposed in two cells, one with exhaust gas with soot and another without soot, has been used by Beck and co. to measure the soot. A potentiometric sensor [10] was used by Vogel and coworkers to detect the soot by burning of soot particulates at the working electrode (zirconia) and measuring the resulting electromagnetic force (e.m.f) in the sensor material. Optical detection [11] is another alternative patented by Schittenhelm, by measuring the decrease of the reflective capacity of a solid surface. The measurement of the electrical resistance of a soot layer deposited between two electrical contacts as a measure of the deposited amount of soot has been used in several patents $[12,13]$.

None of these papers or patents refers to the thermophoresis phenomenon as a basis for the soot deposition between the electrodes. The resistivity technique has been illustrated for both collection and regenerative burn-off for a sensor exposed to an open diesel flame [14]. Collection on the sensor's surface (interdigitated platinum electrodes on an alumina substrate) was done at $350^{\circ} \mathrm{C}$, a temperature high enough to avoid water vapor condensation but low enough to prevent significant soot combustion on the platinum electrodes. The authors did not actively create a temperature gradient between the soot in the gas-phase and the sensor surface, nor did they mention the influence of thermophoresis. No information about the soot deposition mechanism was given.

Temperature is an important parameter for collection of aerosol particles. Thermophoresis is a force resulting from a temperature gradient being established in the gas phase [15]. Since gas molecules coming from the warmer area have a higher velocity than those coming from the cooler area, aerosol particles receive a net momentum toward the cooler zone. A solid surface at lower temperature than the ambient thus can serve as a precipitator for aerosols. Thermophoresis has been used for size independent deposition of Ag particles from polydisperse aerosols [16] and removal of particles from diesel exhaust [17]. Such high collection efficiencies are not necessary for sensor purposes but the temperature gradient must be sufficient to obtain reasonable response times. Soot sensors may potentially be used to control the regeneration of the particle filter in diesel engine vehicles in order to avoid overheating due to an overload of soot. Quantitative measurements would make On Board Diagnostics, OBD, possible. For the OBD application with a sensor position after the particulate filter, a very high sensitivity to soot particles is required. Here we present the first results for the development of a thermophoretic soot sensor and show results from soot collection on resistivity sensor surfaces, both in laboratory conditions and in real diesel engine exhaust. We think that the method has potential for

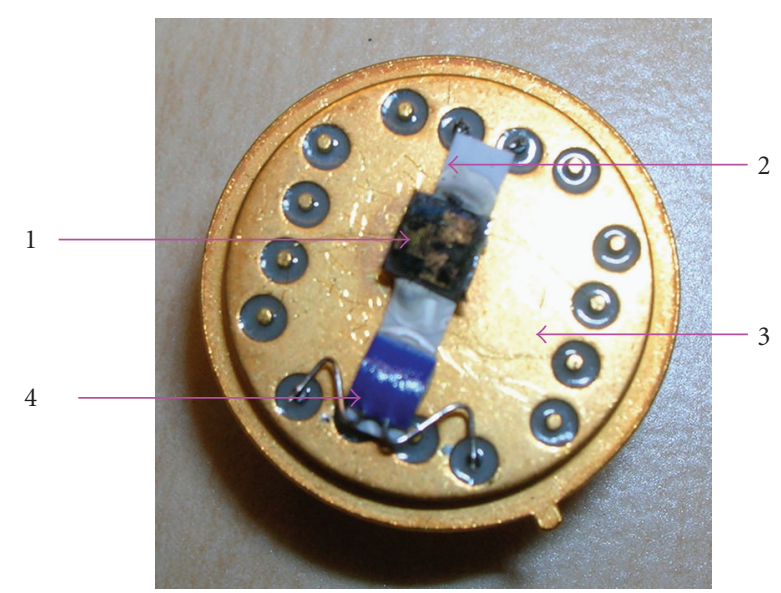

Figure 1: The sensor mounted on a heater with a Pt 100 temperature sensor.

a soot detector employing high-sensitivity and low-detection limit.

\section{Experimental}

The substrate for the soot detection (1) consisted of a finger electrode structure of $\mathrm{Ti}$ and $\mathrm{Au}$ sputter deposited on a thermally oxidized $\mathrm{Si}$ substrate, $\mathrm{Si} / \mathrm{SiO}_{2}(100 \mathrm{~nm}) / \mathrm{Ti}$ $(5 \mathrm{~nm}) / \mathrm{Au}(200 \mathrm{~nm})$. The finger electrode structure on the wafer was obtained using lift-off technology. The width of the electrodes was $80 \mu \mathrm{m}$ and the two gap distances tested were 80 and $300 \mu \mathrm{m}$.

The substrate was then cut into small pieces, each containing a single pair of interdigitated electrodes. These were mounted on a heater ( $\mathrm{Pt}$ wire in an $\mathrm{Al}_{2} \mathrm{O}_{3}$ substrate from Heraeus) substrate (2) positioned in a 16-pin holder (3) where a Pt 100 sensor (Pt resistor with the resistance $100 \mathrm{Ohm}$ at $0^{\circ} \mathrm{C}$ ) (4) allowed temperature measurement; see Figure 1. The holder was placed in a sealed cell and exposed to soot containing gas flows.

Soot was generated by a diffusion flame using propane as fuel. An air-to-fuel ratio of about 3.5 (in moles oxygen per mole propane) was used. This flow was diluted with compressed air directly after the flame in order to quench the soot and stabilize the degree of agglomeration (through coagulation). A second dilution step with air using an ejector diluter (Dekati, Finland) was subsequently applied in order to decrease the soot concentration further. Final dilution levels, expressed as ratio of flame air volume to dilution air volume, are given in the results section. The soot particle size distribution after the dilution was measured by a

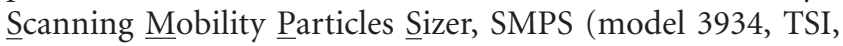
Inc). The geometric mean particle diameters were on the order of $100 \mathrm{~nm}$. Dependent on dilution, the average number concentration varied between $5 \times 10^{5}$ and $5 \times 10^{6} \mathrm{~cm}^{-3}$.

A simple deposition cell, where a thermal gradient was established between the sensor surface and the gas stream, was constructed. Since thermophoretic deposition of the soot particles was favored by the contact of the gas flow 
with a cooler surface, the diluted soot flow was heated to $240-270^{\circ} \mathrm{C}$ before deposition by passing it through a steel tube heated by an electrical heater. The sensor was heated somewhat by the gas stream and the temperature during the measurements, as measured by the Pt 100 sensor, was in the range of $105-125^{\circ} \mathrm{C}$. The soot containing flow went through the soot deposition cell at a flowrate of 1 liter/minute. These temperatures were sufficiently high to prevent water condensation at the dilution levels used. Soot layer morphology was investigated by SEM using a Leo $1550 \mathrm{VP}$ emission field scanning electron microscope.

The resistance measurements were performed using a multimeter device (TTI 1604) capable of measuring in the resistance range from $1 \mathrm{kOhm}$ to $20 \mathrm{MOhms}$.

Sensors for measurements in diesel exhaust were prepared by screen printing PtPdAu conductor (DuPont) on alumina substrates $(90 \times 5 \times 1 \mathrm{~mm})$. After firing at $850^{\circ} \mathrm{C}$, the ink had a resistivity of $100 \mathrm{MOhm} / \mathrm{sq}$ (this processing was performed by Selmic Oy, Finland). The interdigitated electrode area was $2 \times 2 \mathrm{~mm}$ and width/gap of the fingers $150 / 100 \mu \mathrm{m}$. A ceramic heater (Heraeus, Germany) was glued with Resbond GF907 (Cotronics Corporation, USA) on the backside of the substrate under the sensor fingers. A Pt100 thermoelement was positioned beside the fingers. The substrate was placed inside a $75 \mathrm{~mm}$ stainless steel tube $(10 \mathrm{~mm}$ o.d.) having half of the tube cut out of a $5 \mathrm{~mm}$ section at one end to allow exposure of the finger structure to exhaust gas and the assembly was sealed with Resbond. Electrical connections for the sensor, heater, and thermoelement were made at the other end of the substrate.

Diesel exhaust was produced by an engine mounted in a standard test cell, able to generate steady-state conditions or standard driving cycles. The sensor was mounted in a bushing welded to the exhaust pipe by Swagelok coupling (the Swagelok Company, USA) with the finger structure positioned in the center of the $7 \mathrm{~cm}$ o.d. pipe, located about a half meter downstream of a closely coupled diesel oxidation catalyst. A fan simulated wind conditions during the test. Reference soot concentrations were measured using a Differential Mobility Spectrometer DMS500 Transient Engine Particulate Analyser (Cambustion Ltd., UK).

\section{Results and Discussions}

3.1. Tests in Laboratory Generated Soot. Soot mainly consists of carbon-rich particles with portions similar to fullerenes and/or graphite-like [5]. The significant number of double bonds and high number of mobile electrons provide graphite-like conducting properties. The morphology of soot deposited on a surface consists of aggregates of spherules having a strong tendency to associate and form curly disordered filaments as shown in Figure 2.

For sensing purposes, the deposition of soot leads to the formation of multiple disordered bridges between the metallic fingers creating a conductive layer as stipulated by the percolation theory [18]. The soot is built up in patches of bridge-like structures over the surface between the finger electrodes, and at a certain point in the soot concentration,

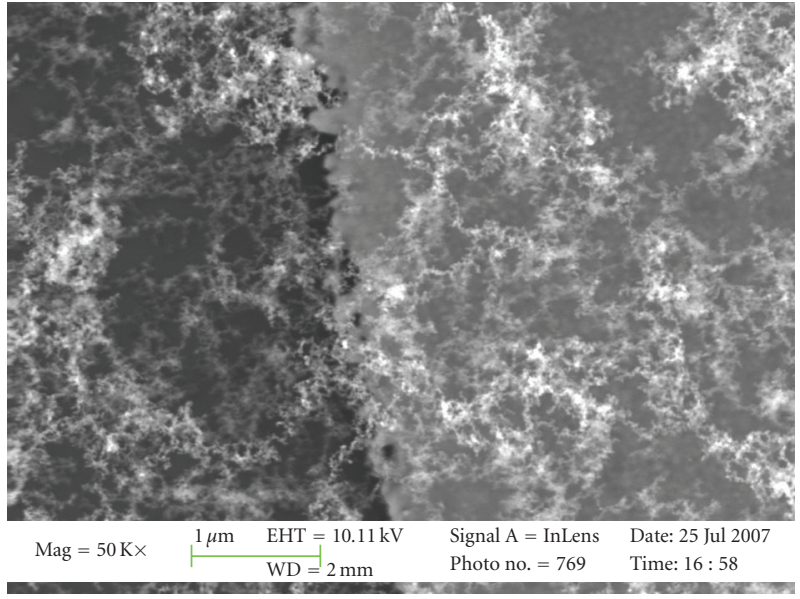

FIgure 2: Typical SEM image of soot (white) deposited onto $\mathrm{SiO}_{2}$ (dark grey, to the left) and the gold electrode (grey, to the right).

there is contact through the whole film, and electrons start to flow from one finger electrode to the other. As the soot deposited amount continues to increase, the conductivity increases by the thickness of the film in a linear way. However, in this kind of film, higher conductivity probably first occurs in some isolated spots. These are first hidden due to higher resistance in the film surrounding these spots but suddenly there is a contact path of spots with higher conductivity all the way from one finger electrode to the other.

It is important to mention here that we did not get any measurable soot deposition if the soot containing flow was cooled down to room temperature prior to passing the exposure cell held at room temperature, even after more than one hour. Quenching (dilution and reduction of the temperature to ambient conditions) of the soot stream was necessary for the SMPS, used as a reference of soot size distribution and concentration. In order to further confirm the importance of the thermophoretic effect on the soot deposition, we heated the sensor surface to $200-400^{\circ} \mathrm{C}$ while subjecting it with a soot containing gas flow of approximately the same temperature. The nonheated 16-pin sensor holder, see Figure 1, was covered with a rich velvet-like soot layer, while the heater with sensor remained totally clean.

Since initial soot deposits are insulated from one another, a delay is expected before a resistance decrease is registered. Figure 3 shows the electrical resistance over time during soot deposition on a substrate with $80 \mu \mathrm{m}$ spacing between the electrodes, using a dilution ratio of the soot flow of $1 / 10$ and at a gas flow temperature of $270^{\circ} \mathrm{C}$. The sensor surface was only heated by the gas stream as described in the experimental section. At the moment when the electrical resistance of the soot layer reached a measurable value, the surface temperature was $105^{\circ} \mathrm{C}$ and continued to increase slightly up to $125^{\circ} \mathrm{C}$ during the subsequent soot deposition. Before a continuous layer of soot was deposited on the substrate surface, the resistance value between the finger structures was out of the measurable range (i.e., larger than $20 \mathrm{MOhm}$ ). Therefore, a short delay (around 5 minutes) was observed before the resistance decreased rapidly and could 


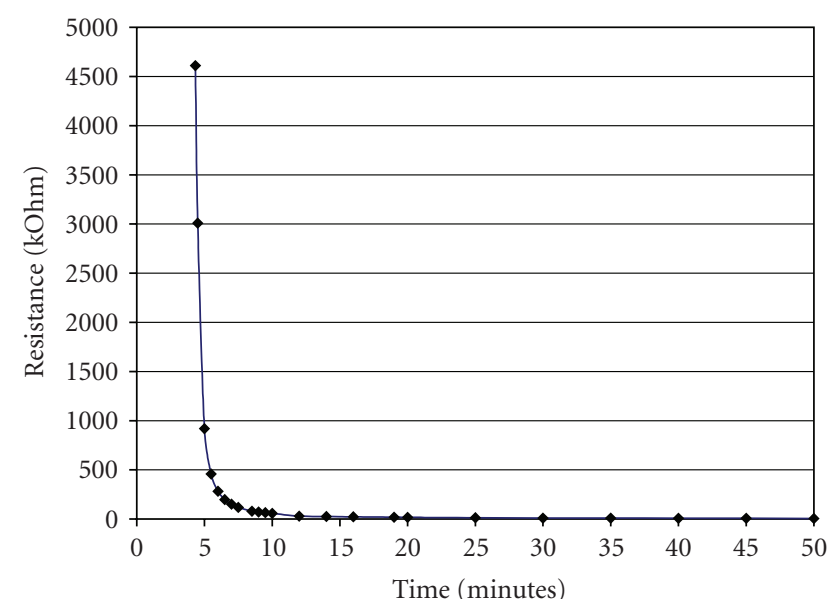

Figure 3: Resistance values upon soot deposition on soot sensor with $80 \mu \mathrm{m}$ between the finger electrodes (total dilution ratio $1 / 10$, gas flow $1 \mathrm{~L} / \mathrm{min}$ and gas temperature $270^{\circ} \mathrm{C}$, sensor temperature: $\left.105-125^{\circ} \mathrm{C}\right)$.

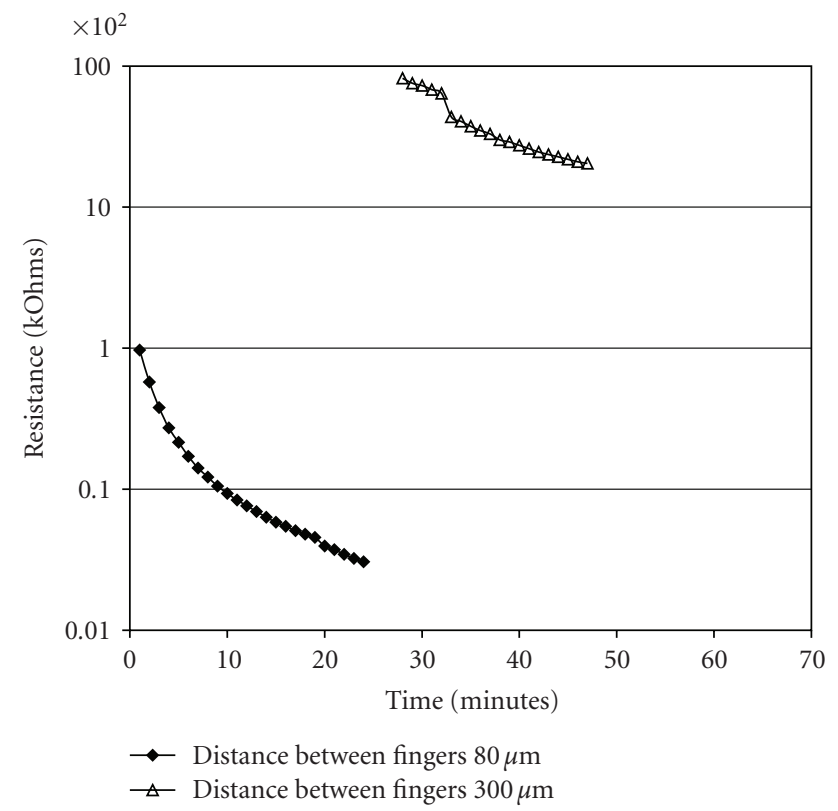

FIGURe 4: Resistance values evolution in time for different distances between electrodes-logarithmic scale (dilution ratio: 1/100; gas flow $1 \mathrm{~L} / \mathrm{min}$ and gas temperature: $240^{\circ} \mathrm{C}$, sensor temperature: $105-$ $\left.125^{\circ} \mathrm{C}\right)$.

be measured by the multimeter. After the rapid decrease corresponding to an increased density of soot particles between the electrodes, the resistance began to level off 10 minutes after the exposure was started and a final resistance of a few $\mathrm{kOhm}$ was reached after 50 minutes.

The time delay for the initial resistance decrease was observed to be strongly dependent on the distance between the metal finger electrodes as shown in Figure 4.

The development of a conducting soot layer between the electrodes required a significantly longer time for the larger electrode spacing. In addition, the observed resistance

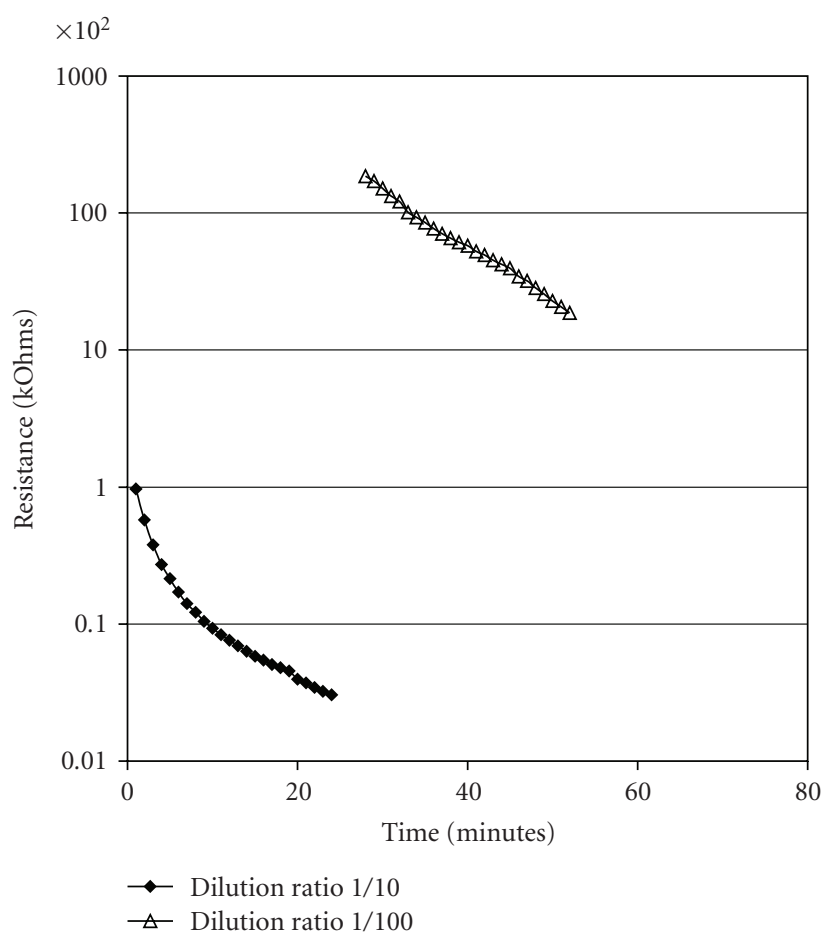

Figure 5: Resistance values evolution by time for two different total dilution ratios (1/10 and 1/100); gas flow $1 \mathrm{~L} / \mathrm{min}$ and gas temperature: $240^{\circ} \mathrm{C}$, soot sensor temperature: $105-125^{\circ} \mathrm{C}, 80 \mu \mathrm{m}$ distance between electrodes.

decrease was considerably lower. It should also be noted that the reason why the resistance change was slower for the $80 \mu \mathrm{m}$ sensor at the Figure 4 conditions as compared to Figure 3 is because of the higher particle stream dilution (1:100 as compared to $1: 10$, gas flow is kept constant at $1 \mathrm{~L} / \mathrm{min}$ ) and slightly lower temperature gradient (gas stream at $240^{\circ} \mathrm{C}$ ).

The effect of soot concentration in the gas flow on the resistance change is further illustrated in Figure 5. A comparison between the deposition of soot at dilution ratios of 1/10 (high-soot concentration) and 1/100 (low-soot concentration) are shown. The observed difference between the two concentrations was similar to what was observed for the two electrode distances shown in Figure 4 with the lower concentration exhibiting a significantly slower resistance change. Then the time resolution of the multimeter also allowed the resistance measurements to start at a much higher absolute value. The curves shown in Figures 4 and 5 also contain occasional stepwise changes in the resistance similar to what has been previously observed for undiluted diesel soot [13]. It should also be pointed out with regard to the large difference in resistance between the devices in Figures 4 and 5 that resistance is a parameter that often shows large variations. The stepwise changes in Figures 4 and 5 may be explained in terms of percolation theory [15] as in connection to Figure 2. Normalized response is therefore mostly used but was not practical in the demonstration of the new method here. We would also like to emphasize that the soot deposition was very slow when using a nonheated 
gas flow of soot particles; we could not enter the measurable resistance range of the instrument after one hour of soot flow through the sensor cell.

The preliminary results in this paper show the potential of the thermophoresis coupled with resistivity detection for a soot sensor concept. It is also important to establish the dependence of the temperature gradient between the gas stream and sensor surface on the soot deposition. This parameter will affect the detection limit and the sensitivity of the device. Regeneration of the sensor surface from soot by heating must also be developed, for example, through cyclical measurements by the sensor. Further research work is now in progress to develop a calibration method for soot sensors using aerosol technology for controlled particle generation and optimized thermophoretic deposition for soot collection [19].

3.2. Diesel Exhaust Measurements. On the basis of the initial results, we performed soot detection in real diesel exhaust systems. Screen-printed sensors were tested in the exhaust system of the stationary motor, in a cycle with and without Exhaust Gas Recirculation (EGR). EGR is a way to reduce the amount of nitrogen oxides formed from the direct reaction between oxygen and nitrogen, occurring at the high temperatures in the engine. Some of the exhaust gas is shunted back into the engine, after previous cooling, instead of a part of fresh air. EGR decreases the temperature in the combustion chamber, thus limiting the NOx formation.

On another hand, the complete combustion of the heavy hydrocarbons from the diesel fuel needs an excess air. There is thus a contradiction between the tendency of soot and NOx formation and a compromise is needed in order to diminish both hazardous exhaust components. In the measurements we performed, the soot concentration in the exhaust gas increased from 1 to $19 \mathrm{mg} / \mathrm{m}^{3}$, as estimated from the DMS measurements, with EGR. A comparison between the soot particle number size distribution, with and without EGR, is displayed in Figure 6 below. The diesel engine was running at $2500 \mathrm{rpm}, 200 \mathrm{Nm}$ och $40 \%$ EGR.

As expected, the soot concentration was significantly higher during the high-load conditions with the EGR activated as compared to EGR disconnected.

The sensor was exposed to the higher soot concentration shown in Figure 6, from $t=0$ to $600 \mathrm{~s}$, and the corresponding soot deposition and measurement is displayed in Figure 7. below. The exposure cycle to soot consists of $600 \mathrm{~s}$ of emission with EGR activated, followed by $300 \mathrm{~s}$ of EGR off at a gas temperature of $210^{\circ} \mathrm{C}$, then by the heating of the sensor at $750^{\circ} \mathrm{C}$ to remove the deposited soot.

As shown in Figure 7, there was an accumulation time of about $300 \mathrm{~s}$ before a resistance decrease was registered. This time was needed for the deposition of a continuous soot conductive layer, similar to what is described for the lab work above. A lower soot concentration at $600 \mathrm{~s}$, as read from the DMS500, caused a slight increase in resistance, possibly due to low mechanical stability of the soot layer. The heating started at $900 \mathrm{~s}$ and caused an initial decrease in resistance, followed by an increase, as the deposited soot was burned off.

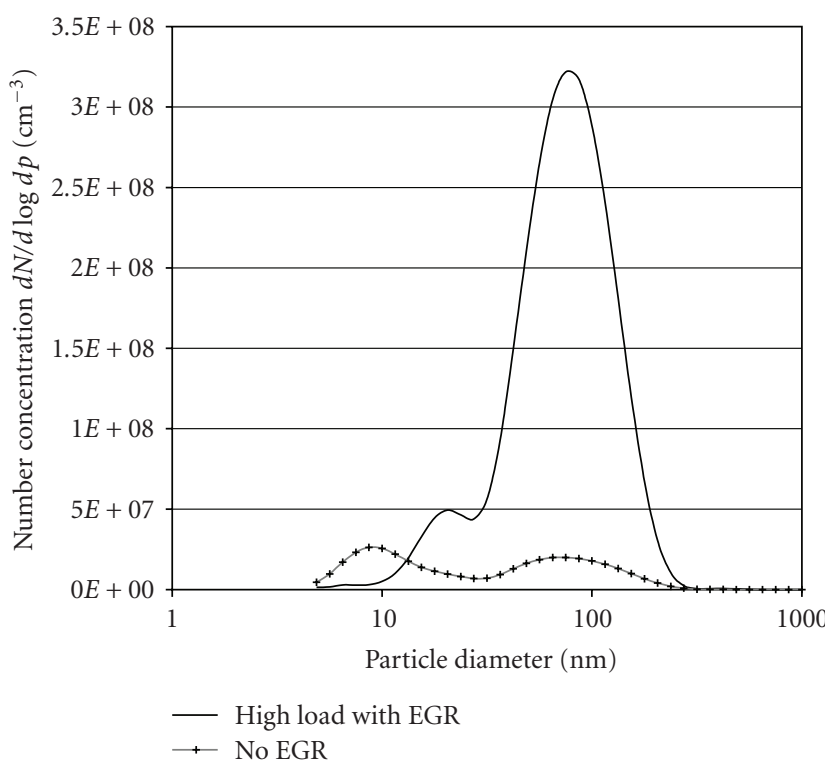

FIgure 6: Particle size distribution of soot during the high load conditions with EGR and without EGR.

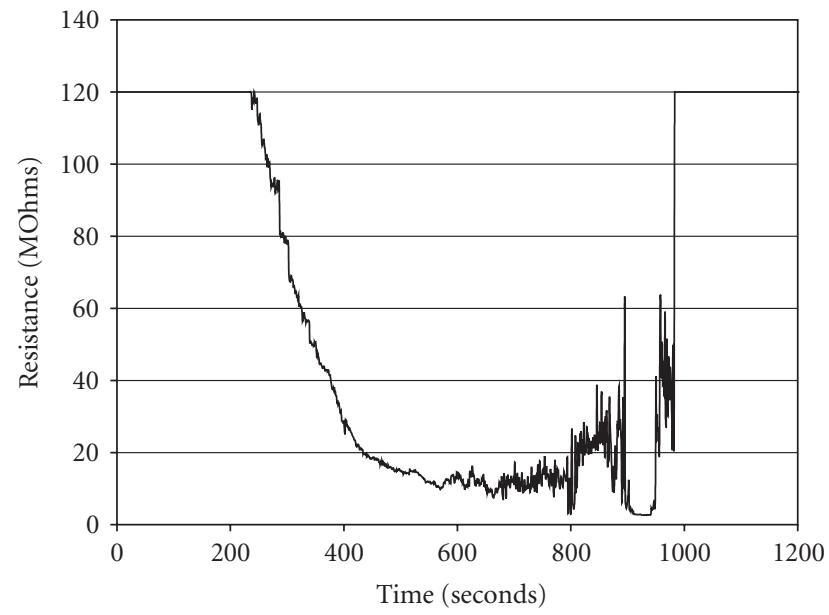

FIGURE 7: Resistance of screen printed sensor during steady-state driving for the stationary motor, exhaust gas temperature $210^{\circ} \mathrm{C}$ $\left(t=0\right.$ : start of EGR, sensor temperature $180^{\circ} \mathrm{C} ; t=600 \mathrm{~s}-$ EGR disconnected, sensor temperature $180^{\circ} \mathrm{C} ; t=900 \mathrm{~s}$, sensor temperature increases to $750^{\circ} \mathrm{C}$ ).

The increase of the resistance could be due to the evaporation of the volatile compounds from the soot, less conductive than the "pure solid" deposited carbonaceous material. The return to the original high-resistance level was rapid as compared to the decrease from soot deposition, because of the quick disappearance of the conductive soot layer by burning.

\section{Conclusions}

Soot particles were generated in the laboratory using aerosol technology (a laminar diffusion flame) or generated by a diesel engine. The soot particles were detected by resistivity sensors employing thermophoresis as the particle deposition 
mechanism. Resistance changes were observed after a certain accumulation of the soot on the surface in accordance with percolation theory. The resistance changes of the collected layers strongly depended on the electrode spacing and the soot particle concentration. The sensors could possibly be used for detection of cracks in the particle filter, monitoring of filter regeneration, and, with proper calibration, quantitative determination of particle emissions after the filter for OBD.

\section{Acknowledgments}

Grant support is acknowledged from VINNOVA (Swedish Governmental Agency for Innovation Systems), NICe (Nordic Innovation Center), the VINN Excellence Center in Research \& Innovation on Functional Nanostructured Materials (FunMat), and the CECOST program by the Swedish Energy Agency. Support is also acknowledged by Volvo Technology and Ford Motor Company. D. Lutic acknowledges Lund and Linköping Universities for a postdoc fellowship. J. Pagels was financed by the Swedish Research Council FORMAS.

\section{References}

[1] M. Matti Maricq, "Chemical characterization of particulate emissions from diesel engines: a review," Journal of Aerosol Science, vol. 38, no. 11, pp. 1079-1118, 2007.

[2] D. S. Su, A. Serafino, J.-O. Müller, R. E. Jentoft, R. Schlögl, and S. Fiorito, "Cytotoxicity and inflammatory potential of soot particles of low-emission diesel engines," Environmental Science and Technology, vol. 42, no. 5, pp. 1761-1765, 2008.

[3] A. Valavanidis, K. Fiotakis, and T. Vlachogianni, "Airborne particulate matter and human health: toxicological assessment and importance of size and composition of particles for oxidative damage and carcinogenic mechanisms," Journal of Environmental Science and Health Part C, vol. 26, no. 4, pp. 339-362, 2008.

[4] "Regulation (EC) No 715/2007 of the European Parliament and of the Council of 20 June 2007," http://eur-lex.europa .eu/LexUriServ/LexUriServ.do?uri=OJ:L:2007:171:0001:0016: $\mathrm{EN}: \mathrm{PDF}$.

[5] H. Burtscher, "Physical characterization of particulate emissions from diesel engines: a review," Journal of Aerosol Science, vol. 36, no. 7, pp. 896-932, 2005.

[6] H. Patashnick and G. Rupprecht, "Carbon particulate monitor with preseparator,” US Patent no. 5279970, 1994.

[7] H. Patashnick and G. Rupprecht, US Patent no. 5196170, 1993.

[8] H. Schittenhelm, WO 2005/024400A1, 2004.

[9] D. Verstreken, "Sensors work to reduce auto emissions," Electronic Design, vol. 56, no. 19, pp. 70-71, 2008.

[10] H. A. Beck, R. Niessner, and C. Haisch, "Development and characterization of a mobile photoacoustic sensor for on-line soot emission monitoring in diesel exhaust gas," Analytical and Bioanalytical Chemistry, vol. 375, no. 8, pp. 1136-1143, 2003.

[11] A. Vogel, V. Schüle, G. Baier, and A. Mahl, "Sensor for online in situ measurement of soot concentration in flue gases," Sensors and Actuators B, vol. 19, no. 1-3, pp. 546-550, 1994.

[12] K. Wienand, M. Murziol, T. Asmus, K. Ullrich, A. Ogrzewalla, and D. Teusch, "Soot sensor," WO 2006/111386 A1, 2006.
[13] R. Sabine, O. Thorsten, K. Bernhard, and H. Schittenhelm, "Sensor element for particle sensors and method for operating the same," WO 2006/077197, 2006.

[14] M. Fleischer, R. Pohle, K. Wiesner, and H. Meixner, "Soot sensor for exhaust gases," in Proceedings of the Eurosensors XIX, Barcelona, Spain, 2005.

[15] W. C. Hinds, Aerosol Technology: Properties, Behavior and Measurement of Airborne Particles, John Wiley \& Sons, New York, NY, USA, 2nd edition, 1999.

[16] R. Lorenzo, R. Kaegi, R. Gehrig, L. Scherrer, B. Grobéty, and H. Burtscher, "A thermophoretic precipitator for the representative collection of atmospheric ultrafine particles for microscopic analysis," Aerosol Science and Technology, vol. 41, no. 10, pp. 934-943, 2007.

[17] A. Messerer, R. Niessner, and U. Pöschl, "Thermophoretic deposition of soot aerosol particles under experimental conditions relevant for modern diesel engine exhaust gas systems," Journal of Aerosol Science, vol. 34, no. 8, pp. 1009-1021, 2003.

[18] D. Stauffer and A. Aharony, Introduction to Percolation Theory, Taylor and Francis, London, UK, 1992.

[19] A. Malik, H. Abdulhamid, J. Pagels, et al., "Generation of diesel like soot particles and thermophoretic deposition on resistivity soot sensor," Aerosol Science and Technology. Accepted. 

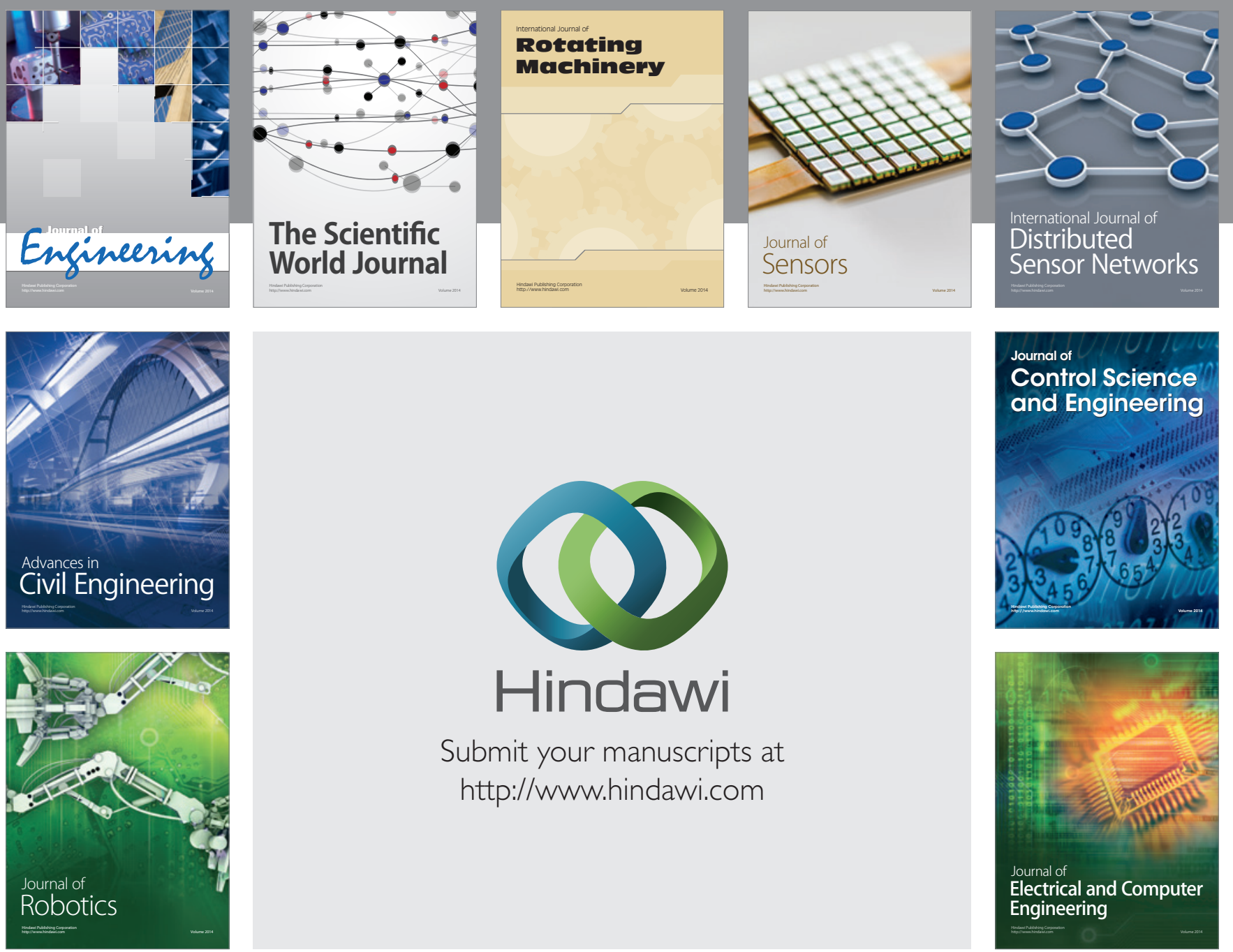

Submit your manuscripts at

http://www.hindawi.com
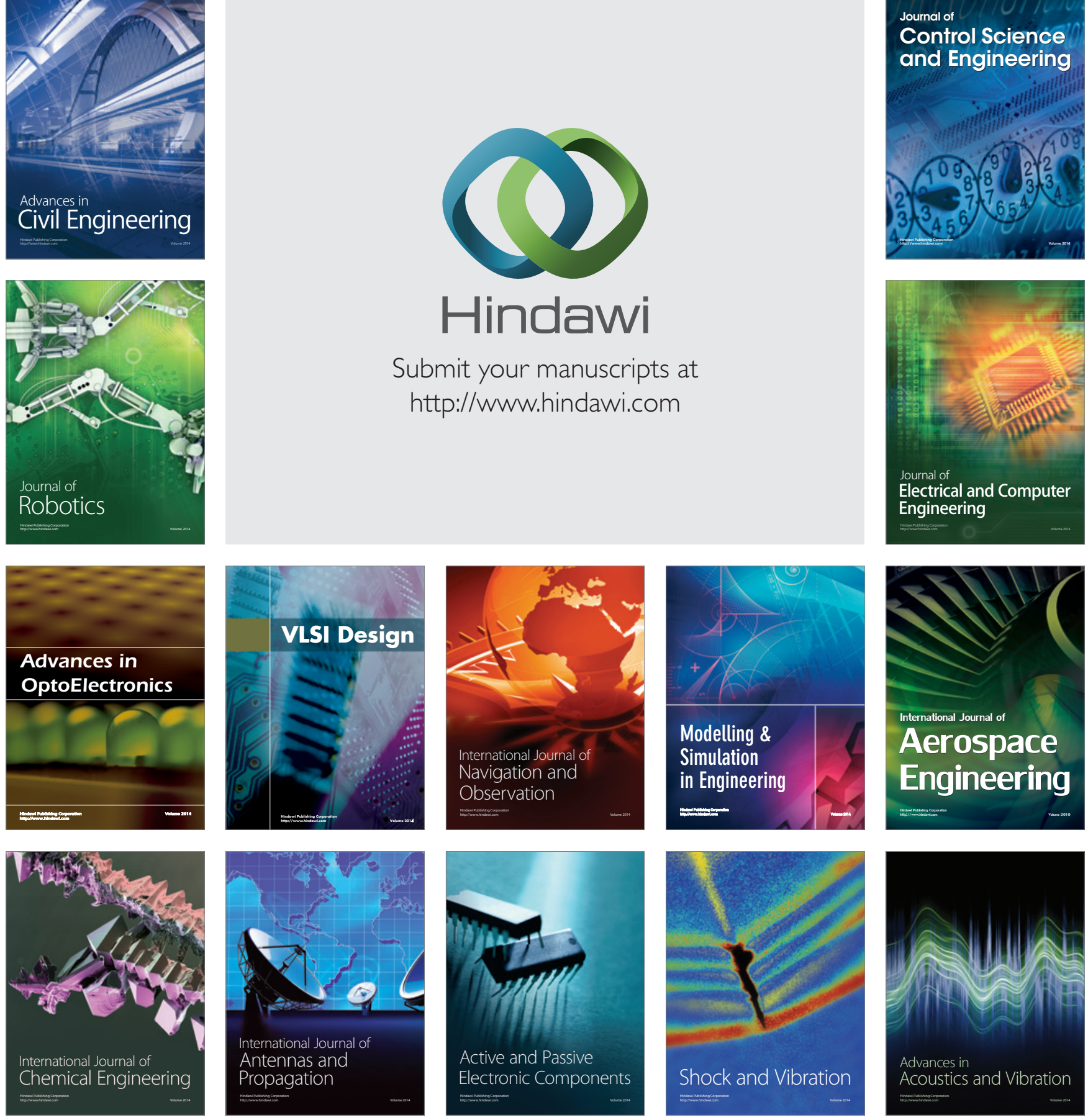